Article

\title{
Exo Journalism: A Conceptual Approach to a Hybrid Formula between Journalism and Artificial Intelligence
}

\author{
Santiago Tejedor ${ }^{1, *(1)}$ and Pere Vila ${ }^{2, *}$ \\ 1 Department of Journalism and Communication Sciences, Autonomous University of Barcelona, \\ 08193 Barcelona, Spain \\ 2 Technological Strategy of the Spanish Radio and Television Corporation (RTVE), 28223 Madrid, Spain \\ * Correspondence: santiago.tejedor@uab.cat (S.T.); pere.vila@rtve.es (P.V.); Tel.: +34-647-61-88-19 (P.V.)
}

\section{check for} updates

Citation: Tejedor, Santiago, and Pere Vila. 2021. Exo Journalism: A Conceptual Approach to a Hybrid Formula between Journalism and Artificial Intelligence. Journalism and Media 2: 830-840. https://doi.org/ 10.3390/journalmedia2040048

Academic Editors:

Simón Peña-Fernández,

Ainara Larrondo-Ureta and

Koldobika Meso-Ayerdi

Received: 4 November 2021

Accepted: 9 December 2021

Published: 15 December 2021

Publisher's Note: MDPI stays neutral with regard to jurisdictional claims in published maps and institutional affiliations.

Copyright: (c) 2021 by the authors. Licensee MDPI, Basel, Switzerland. This article is an open access article distributed under the terms and conditions of the Creative Commons Attribution (CC BY) license (https:/ / creativecommons.org/licenses/by/ $4.0 /)$.

\begin{abstract}
The irruption of artificial intelligence (AI) and automated technology has substantially changed the journalistic profession, transforming the way of capturing, processing, generating, and distributing information; empowering the work of journalists by modifying the routines and knowledge required by information professionals. This study, which conceptualizes the "exo journalism" on the basis of the impact of AI on the journalism industry, is part of a research project of the Observatory for Information Innovation in the Digital Society (OI2). The results, derived from documentary research supported by case studies and in-depth interviews, propose that AI is a source of innovation and personalization of journalistic content and that it can contribute to the improvement of professional practice, allowing the emergence of a kind of "exo journalist", a conceptual proposal that connects the possibilities of AI with the needs of journalism's own productive routines. The end result is the enhancement of the journalist's skills and the improvement of the news product. The research focuses on conceptualizing a kind of support and complement for journalists in the performance of their tasks based on the possibilities of AI in the automatic generation of content and data verification.
\end{abstract}

Keywords: artificial intelligence; journalism; innovation; automation

\section{Introduction}

The arrival of artificial intelligence in the news industry is creating a new technological media ecology, in which the journalistic profession is undergoing one of its most radical changes. The new narratives in the digital society are generating a reflection on the supports, formats, and evolution of these technologies (Tejedor-Calvo et al. 2020). In this context, AI is being considered as the new vector of technological evolution in the media sector. In this context, the importance of this research, which during these last years has studied the main projects and consulted different professional profiles such as journalists, researchers, and experts in artificial intelligence, to propose the "exo journalist" model as a proposal derived from the analysis of the challenges, transformations, and solutions that AI poses to journalism. Its impact, both on journalistic practice, dissemination, and social perception, has unveiled the need for further research and academic analysis on the subject, a new informative modality that some researchers call "automated journalism" (Caswell and Dörr 2018), "computational journalism" (Vállez and Codina 2018), or "robojournalism" (Carlson 2015). The concept of "exo journalism" goes beyond automation, it seeks to empower the journalist, improving his or her work to limits that had not been achieved so far.

García and Vizoso (2021) explain this intersection between technology and the creation of journalistic content as a field of experimentation in which new and complex automation systems, algorithms, and virtual reality coexist: a territory full of innovations, crossbreeding, and hybridization. In this union, the study positions AI as a tool with great potential to influence in a broad and profound way how journalism is made and how it is consumed 
(Beckett 2019). Thus, some of the hypotheses raised refer to the processes of information collection and selection, to the training of journalists or to the ethical and educational field. As Vállez and Codina (2018) recall, the synergy between both disciplines is an inevitable reality, since trend analyses show that technological evolution not only affects dissemination channels, but also the creation and conceptualization of journalistic content. In this stage of redefinition, as Rivas-de-Roca (2021) explains, the roles of professionals and machines in newsrooms face the challenge of playing automation in journalistic and commercial information. Once again, this is a technological revolution that has as a fundamental pillar an incessant search for defining what it means to do journalism (Salaverría and García 2008). For some professionals, this horizon could provide an encouraging outlook for innovative quality journalism that would allow journalists to move away from the most repetitive and routine tasks and develop more creative ones that add value to journalistic content (Ufarte et al. 2020).

Its incipient nature, and the degree of innovation, adaptation, and assimilation required by AI techniques, has led to many in the media, and journalists, wondering what the degree of usefulness and help does this tool have, and what are the main challenges that will emerge in the exchange between communication, journalism, stories, technology, and the so-called intelligence exhibited by machines (Túñez and Tejedor 2019). Its use has created debates that pick up the replacement of the individual by the machine and move to the field of ethics and job loss (Villoro 2017), the veracity of content and the creation of new spheres of control over the information that is published. This new journalistic practice is providing a series of challenges that include the guarantee of privacy and intimacy of individuals, the contrast of information produced by emerging technology, the training of information professionals for its use and application, the detection and control of the biases of algorithms, and the need for a sense of commitment and social responsibility on the part of the journalist.

AI offers numerous possibilities for perfecting, completing, and complementing the daily work of information professionals. This paper tries, in this sense, to theorize about the concept of "exo journalist" as an alliance between journalism and artificial intelligence. The proposal is derived from long-term work of documentary review, case studies, and consultation with experts through the Oi2 project, promoted by Radio Televisión Española (RTVE) and the Gabinete de Comunicación y Educación of the Universidad Autónoma de Barcelona. The analysis model developed by RTVE and the Gabinete de Comunicación y Educación, a research group of the Universidad Autónoma de Barcelona, designed to systematize and structure the study on the introduction of AI in each of the phases of news production, has made it possible to observe pragmatically how the most active media have already introduced some of the numerous tools offered by this technology. In this scenario, gaps are detected as a result of the imposition of journalistic business models that, on many occasions, pit the most valued by journalists against the most viewed by users. This aspect has conditioned the development and consolidation of different initiatives that connect journalistic production routines with the possibilities of $\mathrm{AI}$ in the daily life of the media. On this basis, the work has been organized around the following research questions:

(1) What features of AI contribute to improving journalistic practice?

(2) What are the defining elements of the concepts of "exo journalism"?

(3) What challenges exist at the level of research and development of applied projects in order to consolidate the "exo journalism" proposal?

\section{Framework}

The advance of AI is a global issue that is affecting all sectors of society. In Spain, in December 2020, the National Strategy on Artificial Intelligence (ENIA) was approved with the aim of making greater investments and boosting its development. Among these sectors is that of communication and journalism, of which it is vital to highlight their own changing nature, being branches with a great projection for the development of new tools and proposals. As Flores Vivar (2019) argues, from this analysis, it is initially clear that 
the informational ecosystem and journalism are going through a constructive model of content based on latent and growing algorithmization processes. Some of the terms that are entering the daily journalistic language have to do with algorithms, automation, and robotization (Danzon-Chambaud 2021).

In this union, which Graefe (2016) has described as "a marriage between journalists and machines", and which seems to be still in the process of understanding, voices have emerged that warn about the risks that the excessive use of AI in journalism may entail: Can machines replace journalists, managing to acquire the cognitive part of journalistic work? Can AI be a threat to the health of the information system, increasing the lack of capacity of the individual to distinguish between valuable and negative information? Journalism could suffer a crisis resulting from a lack of adaptation, motivated by too rapid a change within a single generation.

Although AI is being used in multiple newsrooms, one of the real targets captured in the report How will artificial intelligence impact journalism? (2017) by the Associated Press is to reach augmented journalism through the maximum benefits that automation can provide. This same document sets out what the use of AI would, broadly speaking, enable journalists to do:

- Identify patterns, trends, and ideas from multiple sources.

- See things the human eye cannot see.

- Automatically convert data and words into text.

- Convert text into audio and video automatically.

- Analyze and understand user behaviors and analyze scenes from objects.

The documentary review of the main bibliographical references on the subject (books, articles, and reports) has allowed the Oi2 project to systematize a number of contributions or benefits derived from the application of AI to journalism. Basically, these can be summarized in the following points:

1. News detection: AI, through data collection and characterization, selection according to categories and structural grouping, is capable of tracking dozens of sources (such as social networks and comments) or detecting breaking news by keywords that are repeated in real time. Different commercial applications have appeared in this field, such as Dataminr, News Tracer from Reuters, NewsWhip from Associated Press, Bertie from Forbes, Quakebot from Los Angeles Times, or Social Media Radar.

2. Automatic generation of journalistic texts: this is a reality in those media that have opted to include artificial intelligence to improve their information service and at the same time obtain greater performance. It allows the saving of time and resources, the creation of more serializable and customizable content. It also frees the journalist to focus on more qualitative tasks. The areas in which it is most easily applied are sporting events, weather, economic information, and election results. Some text auto-mapping systems are Heliograf from The Washington Post, Cyborg from Bloomberg, Wordsmith from Automated Insights, Quill, developed by Narrative Science, Syllabs, or Editor from The New York Times.

3. Personalization of information: Personalization has become an increasingly popular strategy for news publishers, who hope that it can increase engagement on their sites and enable them to capture data about users, thus reducing their dependence on external providers of information. As information consumption is shifting towards a more selective form, in which the user has greater decision-making power, the media are beginning to apply personalization in headlines, in the text itself, on front pages, in delivery time, or through personalized recommendations in sections or sending push notifications. This use of AI allows the differentiation of products from the competition, greater reader retention of content, and greater user loyalty.

4. Fighting misinformation: the pernicious use of AI allows the creation of deepfakes, which reduce trust in news and contribute to widespread indeterminacy and social cynicism (Vaccari and Chadwick 2020). This problematic has put the focus on the need for media literacy, which enables people to be informed, engaged, and empowered to think critically 
when making decisions (Muratova et al. 2019, p. 16). Some of the tools used are Factmata, Claimbuster, TweetDeck, Factstream, or Hoaxy, among others.

5. Virtual assistants and presenters developed for journalism: this type of equipment is found in a context of unstoppable technological innovation and growing consumption of audiovisual content, and that is why we can see that the evolution of the classic radio or television broadcast to other platforms has taken hold. Currently, there are already numerous media groups in the United States, Europe, and Latin America, such as the BBC, CNN, Reuters, Deutsche Welle (DW), Bio Bio Chile, Radio Programas del Perú, Noticias Colombia, among others, which are joining the list of news applications of the virtual assistants Google Assistant, Alexa (Amazon), and Siri (Apple), whose portfolio is growing steadily.

1. News detection and structure of the information: the journalist is informed and agrees to initiate the process and subsequently validates its continuation.

2. Verification of information and source

3. Gathering of complementary information, analysis, and elaboration of the proposal: the journalist elaborates with the support of the tools and the body of the news and gives his conformity.

In general terms, journalists with the use of AI could increase content production, identify newsworthy events for subsequent dissemination, fight against misinformation, detect the management of profiles in social networks to adapt to user preferences, and obtain greater accuracy and objectivity with search and classification functions. The current trend that has been observed as a result of the topics and case studies analyzed is that there are already robots that create autonomous news from data, machines that facilitate the coverage of atypical situations such as natural disasters, the use of fact-checking to certify the veracity of facts, and audiovisual pieces generated from the recognition of images and feelings.

\section{Results}

The documentary study, developed throughout the Oi2 project, as well as the in-depth interviews and case studies carried out, lead to the conclusion that the grouping of this set of tools with other existing tools would make it possible to configure a kind of support and complement for the journalist in carrying out his or her tasks. This "layer" or support could be explained by the concept of "exo journalist". It is not so much a question of augmented journalism as of improving the journalist's capabilities and possibilities in the performance of his or her tasks.

In the field of medicine, the concept of exoskeleton is defined as a structure to be worn on the human body as a garment, as described by the English term "wearable robots". It is an element that serves as a support and is used to assist the movements and/or increase the capabilities of the human body. They can be passive or active structures, i.e., they may or may not contain actuators for movement and therefore may or may not need a control system associated with the actuation of these actuators. Based on the above and on the results obtained in the five reports developed, the study suggests that the possibility of developing and implementing tools of this type also emerges in the field of journalism, which can support and assist the work and increase the possibilities/capabilities of the journalist.

This concept or idea would mean a reinforcement for the journalist in the development of the stages and tasks approached for the production of an informative material. Next, the structure of this tool is proposed, which would be focused and trained for a very specific subject, since it would require a very important base of ontologies and stories. The proposal of an "exo journalist" would respond to the following work dynamics organized in five stages (Figure 1): 
News detection and structure of the information

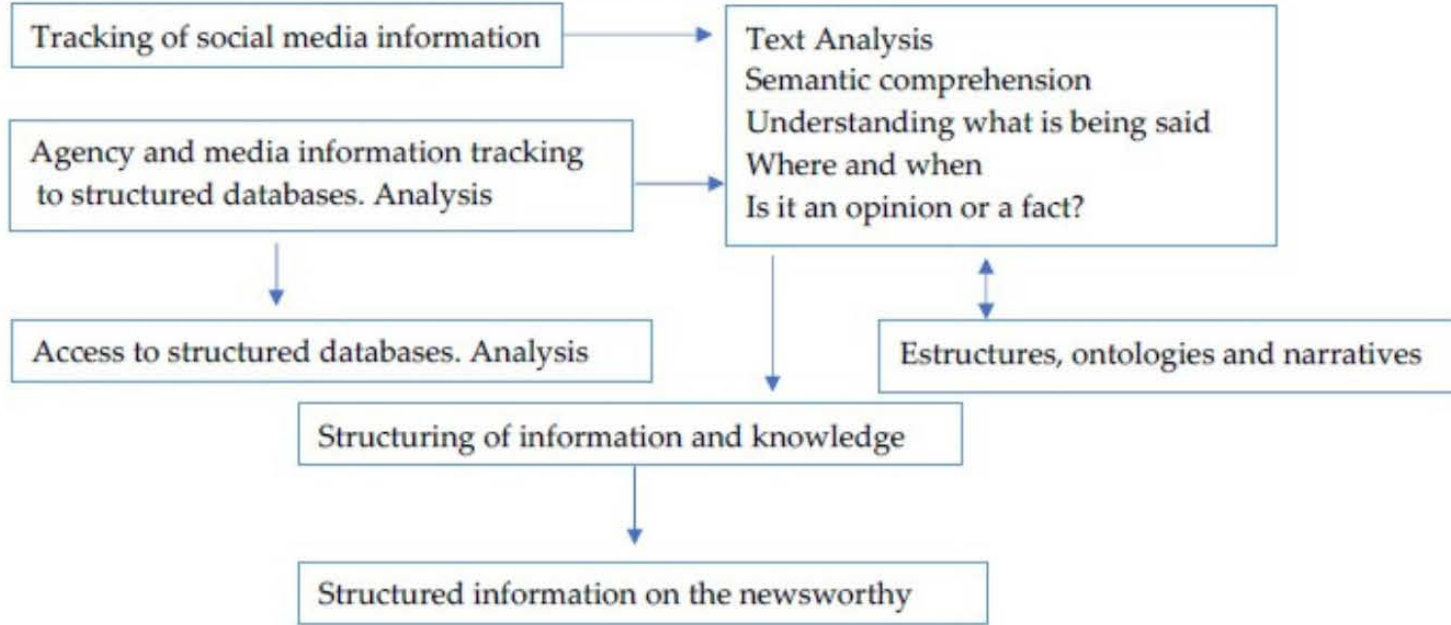

Verification of information and source

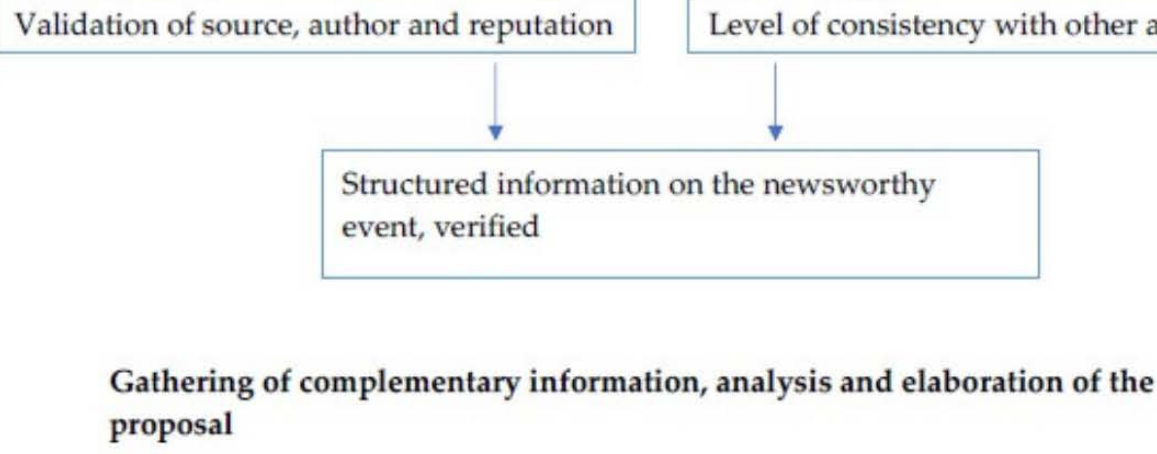

Structured information on the newsworthy event, verified

\section{Gathering of complementary information, analysis and elaboration of the proposal}

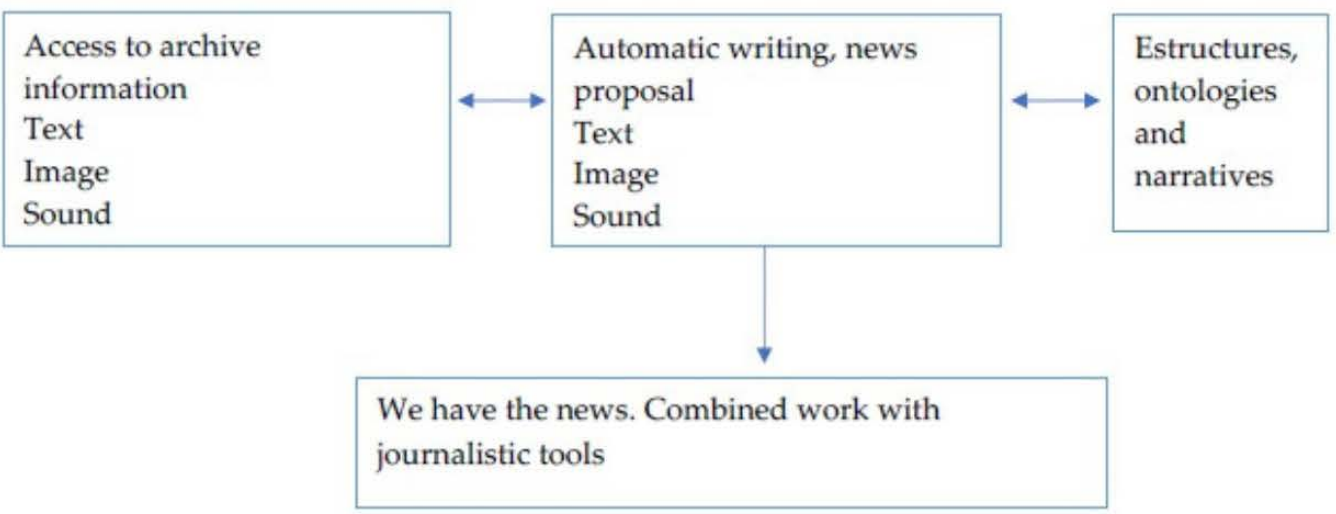

Figure 1. (Source: own elaboration).

- $\quad$ Stage 01: Detection of the news and structuring of the information. The journalist is informed and agrees to start the process and subsequently validates it for its continuation. In this phase, the "Tracking of information in social networks" and the "Tracking of information from agencies and media" take place. Based on this, the text is analyzed from the following aspects: semantic comprehension, understanding what is being said; identifying the where and when; differentiating whether it is an opinion or a fact; establishing whether it is located in the past, present, or future. In this phase, an initial information search is carried out based on agency and media 
content. In addition, access to structured databases (analysis) is produced and possible structures, ontologies, and narratives are processed. All this leads to the conformation of structured information on the news event addressed.

- Stage 02: Verification of the information and the source. In this stage, the source, its author, and reputation are validated. In addition, the level of coherence with other information is analyzed. In this way, structured information on the newsworthy fact is accessed, which has already passed a first level of verification.

- Stage 03: Gathering of complementary information, analysis, and elaboration of the proposal. The journalist elaborates with the support of the tools and the body of the news and gives his conformity. In this phase, archival information (text, image, and sound) is accessed. In addition, an automatic drafting (news proposal) is carried out. The result is the news piece derived from a combined work between the journalist and the technological tools that assist him/her.

- Stage 04: Publication and personalization. The publication and personalization process begins, with a double dimension, one on media and social networks and the other for different groups. The publication for media and social networks is supported by a process of personalization by groups.

- Stage 05: Collection of user feedback and evaluation of the work. The last stage focuses on compiling feedback from comments received through different media and channels.

Based on the above, it is possible to affirm that the proposal of the "exo journalist" offers aspects of great value for the improvement of journalistic practice. It is about materializing a series of possibilities that have already been identified by some works, such as the study of ethical and legal problems related to AI in the press (2018), and that demand conceptual approaches and applied research that connect with the proposal of the "exo journalist". They could be gathered in the following points that delimit the challenges of this conceptual proposal that connects the possibilities of AI with the demands derived from journalistic production routines.

- Increased knowledge: there is a shared feeling in the sector that communication professionals should begin to study this technology in depth, since it will substantially affect them, both in their work routines and in the knowledge and skills required.

- Need for transparency: Who is responsible for the information pieces produced by algorithms? Should the criteria by which automated news are produced and published be transparent? The work of journalists could insist on the contrast of the information produced automatically.

- Privacy guarantee: the use of AI for content personalization brings to the table the need and duty to guarantee users' privacy and intimacy. This raises the possibility of developing an ethical framework for AI and journalism that includes codes of conduct for programmers and journalists.

- Fake News: bias-free artificial intelligence is one of the great challenges. Algorithms have been shown to have biases that can end up weighing down the credibility of the media. This problem has led to the birth of new journalistic profiles, the fact-checkers, or information verifiers.

- Authorship: the generation of works by artificial intelligence could have very important implications for copyright. Countries such as China have already determined that a work generated by artificial intelligence qualifies for copyright protection. Given that AIs do not write on their own and require input from humans, what should be protected, the human intervention or the end result? The role of the journalist could change from producer to supervisor of the news produced by the algorithm.

- Ethical component: the rapid evolution of AI systems and their gradual incorporation into newsrooms has made academics consider it necessary to adapt the Code of Ethics of the FAPE (Federation of Spanish Journalists' Associations) to adapt it to journalism with AI, always picking up the UNESCO International Principles of Professional Ethics of Journalism taking into account that, as stressed by the Comisión Comisión 
Europea (2020), a high level of security, protection, and privacy must be guaranteed with respect to the data used for communication between people and robots and artificial intelligence.

- Training: Communication faculties and journalism schools have to adapt their curricula to the new demands of the AI-impacted journalism sector.

\section{Discussion}

The possibilities of applying AI to journalism continue to open new horizons and ways of understanding the profession. García and Vizoso (2021) argue that the future of journalism is a current debate in constant construction and evolution, in which researchers and different sectors of society will seek answers to help make this synergy a viable connection, all in a global context of digital society. In this scenario of such accelerated changes, research and academic divulgation become essential. Currently there are international and national media that have developed their first experiences and prototypes based on artificial intelligence systems.

Some authors have defined AI as a branch of computer science that studies the possibility of a machine developing its own tasks based on its two most particular features, such as reasoning and behavior, while others describe it as a set of rules that, systematically applied to appropriate input data, solve a problem in a finite number of elementary steps (Berlanga de Jesús 2016). For its part, the European Commission, which in 2020 created the White Paper on Artificial Intelligence, a regulation to promote excellence and guarantee the privacy and fundamental rights of European citizens, defines artificial intelligence as a set of software and hardware systems designed by humans that understand their environment by capturing data, reason, and create knowledge and process these data to decide on the best actions to achieve the indicated objective. In short, we are talking about the possibility of machines to be able to think autonomously.

The commercialization and use of AI tools applied to journalism is progressively gaining ground. The data analyzed point to the need to continue with research processes in order to draw a map, as a basis for learning for the present and the future. These analyses delimit two differentiated aspects that have to do with the positive and pernicious uses of AI. On the one hand, there are positions such as those of Whittaker (2018), who point out how the growing weight of technology in the news industry increases the value of commercial decisions to the detriment of journalistic issues, and others such as those of Ufarte et al. (2020), who indicate the positive impact of AI based on the discourse of objectivity and the search for new opportunities. There are journalists who would propose the definition of the "augmented journalist" capable of, thanks to the help of AI, analyzing data, and covering different topics at the same time. In this territory there is also the need to develop a greater scientific background to propose new communicational theories.

In this outline of the relationship between journalism and artificial intelligence, it is computer engineering that is acting as the main agent at the forefront of the sector. Journalistic organizations are not fully aware of the possibilities of these technological innovations. Likewise, it is observed that their application is more feasible in large media, with a strong economic investment and through the search for alliances with educational and technological organizations. This leads to thinking that in local or proximity media, and in small organizations, the application of AI will be slower and more indirect. Innovation processes, in the medium and short term, depend on the capacity to invest in resources, both human and financial.

The future seems to lie in a hybrid formula between the human function of generating data and verifying content and the automated abilities of AI systems. It may be on that horizon that some of the media will have to make a rapid transition from their information transmission model to a more personalized one. Considering the risks that such a change could entail, transparency in the information creation processes seems vital to be able to transmit truthful, quality, and plural information. 
The media face the great challenge of counteracting all the disinformation generated both in their own content and in social networks. In this aspect, a greater effort is being made by different projects and initiatives to fight against disinformation. Artificial intelligence could become a risk or an opportunity for progress depending on the use that the journalistic profession makes of it. This emphasizes the need to establish a continuous dialogue between engineers, researchers, communication academics, and journalists in order to establish a mutual understanding and a correct development. In this scenario, the role of media literacy is fundamental to ensure that citizens understand the true role that AI can play and, on the other hand, to avoid the prejudices that have been built around these technological advances and their impact on journalism and other scenarios in our societies.

\section{Materials and Methods}

This paper presents the results of a descriptive, explanatory, and exploratory research that is part of a research process of the Observatory for News Innovation in the Information Society (OI2), a collaborative project between Radio Televisión Española (RTVE) and the Autonomous University of Barcelona. The initiative began in 2015, the year in which the Observatory was constituted and a joint chair on the same topic was created. Since 2015, Observatorio OI2 and the RTVE-UAB Chair have developed a continuous series of activities (among them: conferences, debates, seminars, research reports, and experiments) aimed at exploring and implementing the innovation capabilities that both technology and the advancement of knowledge in general are opening up in recent times. AI has played a leading role in this research project that has been developed over 6 years. The fundamental objective of all these activities has been to discover future trends in the sector and to anticipate, through development and training strategies, foreseeable changes.

From a methodological point of view, this work initially focused on breaking down an abstract subject into different fields of action in which artificial intelligence can provide very specific tools and solutions that can help and complement the work of journalists in this new digital society. Aspects such as pre-alert systems for journalists, help in the preparation of non-news, automatic text writing systems, tools for the personalization of the offer and contents, tools to help in the detection of Fake News, automatic metadata systems, sentiment analysis in social networks, and virtual presenters have been references of study.

For each of these references, a common working methodology was designed and applied, consisting of studying the scientific basis of these methods, both journalistic and technical, understanding the technologies on which the solutions currently on the market are based, getting to know the companies that are commercializing these products, and analyzing the success stories and possible failures of audiovisual communication companies that have already started to use them. As a result, five reports (Table 1) have been prepared and published on the professional possibilities that exist between journalism and artificial intelligence.

Table 1. Reports prepared by the Observatory for Innovation in the Digital Society (OI2).

\begin{tabular}{cc}
\hline \multicolumn{1}{c}{ Report } & Date of Publication \\
\hline Report 1. News Detection through Artificial Intelligence Applications & March 2020 \\
\hline Report 2. Automatic generation of journalistic texts & May 2020 \\
\hline Report 3. Personalization of audiovisual media content & November 2020 \\
\hline Report 4. Against disinformation: strategies and tools & March 2021 \\
\hline Report 5. Virtual assistants and presenters in journalism & June 2021 \\
\hline
\end{tabular}

Source: Own elaboration.

Based on this documentary work, the research has been based on the case study methodology and on the interview (Table 2). The interview, conceived as an exploratory approach, was decisive in gathering reflections on a phenomenon that, at the journalistic 
level, had been, for the moment, little worked on. In addition, the interviews were of great value in identifying explanatory elements and indications of possible new prospective phenomena. The results of previous research and the opinions of experts on the subject (Ramírez-Montoya and Lugo-Ocando 2020), through interpretative practices of reality (Denzin and Lincoln 2017), have facilitated the descriptive and explanatory work proposed by the research. Thus, the contrast of information is performed by methodological triangulation between semi-structured interviews and documentary sources through a systematic review of the scientific literature as part of the secondary research (Codina 2017). This work has made it possible to confront the most important contributions of the state of the art (Ramírez-Montoya and García-Peñalvo 2018). The sufficient contextualization of the phenomena studied (Calvo-Rubio and Ufarte-Ruiz 2020) has been possible thanks to the selection, in the different in-forms, of profiles of interviewees from different themes, fields, and areas of development.

The research selected 18 experts, a sufficient number to achieve the established objectives, on the one hand, and on the other, to reach the saturation point, conceived as the point at which the interviewees begin to repeat the answers of others. The experts were selected for their background in the fields of journalism, technology, or AI (Manfredi et al. 2020; Calvo-Rubio and Ufarte-Ruiz 2020). The interviews, conducted by telematic means, were carried out during the second half of 2020. In addition, the research conducted 20 case studies ( 9 of professional projects and 11 of tools), between September 2020 and March 2021, on initiatives and platforms focused on content personalization, data verification, and information detection through AI. The case study methodology as a descriptive process of successful experiences (Yacuzzi 2005) is of great value in explanatory and exploratory work due to its inductive value (Stott and Rami 2014).

Table 2. List of case studies: projects and tools.

\begin{tabular}{|c|c|}
\hline Agencia EFE & www.efe.com \\
\hline Diario Sport & www.sport.es \\
\hline Narrativa & $\underline{\text { www.narrativa.com }}$ \\
\hline El Confidencial & $\underline{\text { www.elconfidencial.com }}$ \\
\hline BBC: Beyond Fake News & www.bbc.co.uk/beyondfakenews/ \\
\hline Le Monde: Les Décodeurs - Décodex & www.lemonde.fr/verification \\
\hline RTVE: VerificaRTVE & www.rtve.es/noticias/verificartve/ \\
\hline Agencia de Noticia Xinhua y Sogou & $\underline{\text { www.xinhuanet.com }}$ \\
\hline Maeil Broadcasting Network \& Money Brain & www.mbn.co.kr/ \\
\hline Factmata & https: / / try.factmata.com \\
\hline Claimbuster & https:/ /idir.uta.edu/claimbuster \\
\hline TweetDeck & https://tweetdeck.twitter.com \\
\hline FactStream & www.factstream.co \\
\hline Fake News Debunker & www.invid-project.eu \\
\hline Hoaxy & https://hoaxy.osome.iu.edu \\
\hline Check & https://meedan.com/check \\
\hline Snopes & www.snopes.com \\
\hline Crowdtangle Search & https://apps.crowdtangle.com \\
\hline TinEye & https://tineye.com \\
\hline RevEye & https://bitl.ly/3qsFY2b \\
\hline
\end{tabular}




\section{Conclusions}

The work carried out by the research team of the RTVE-Universidad Autónoma de Barcelona Chair allowed us to visualize a considerable number of successful cases, which, in some cases, were also linked to worldwide reference companies in the audiovisual communication sector. The use of AI is already a reality in the media. The first to use AI was the Los Angeles Times, which, in March 2014, published a news item about an earthquake prepared by Quakebot software. Since then, it has been followed by other U.S. media such as The Washington Post or Reuters, which use advanced automatic writing software. In China, the Xinhua News agency became the first to use virtual news anchors in 2018, and in Europe, The Guardian recently published the first opinion piece written entirely by an artificial intelligence. The UK Press Association, Press Association, in collaboration with URBS Media and through funding from the Google Digital News Initiative, has developed RADAR (Reporters and Data and Robots), the world's only automated local news agency. The Finnish public media Yleisradio has created the world's first virtual news assistant, called 'Voitto', which makes intelligent news recommendations. In Spain there are also several media that already make use of AI through the use of bots, such as El País and El Confidencial. El Periódico de Catalunya and Diario Sport are also working on the generation of automatic texts through the company Narrativa. For its part, RTVE is working on news verification with its VerificaRTVE platform. Its innovation area, in alliance with the technology company Monoceros Labs, in charge of the development of the virtual assistants project, is also achieving improvements in this field.

In the same way that robotics research and industry is advancing along two lines; on the one hand, that of the individual, autonomous robot, which performs tasks unassisted, and on the other, the branch of the so-called exoskeletons, which are an aid and a reinforcement to tasks or activities performed by humans; everything points to the fact that the incorporation of artificial intelligence tools to journalism can also be developed in this way.

As pointed out in the previous sections, the audiovisual and journalistic sector is developing tools for the detection of news through artificial intelligence applications, automatic generation of journalistic texts, personalization of contents in audiovisual media, systems to combat misinformation, and the creation of virtual assistants and presenters in journalism.

Author Contributions: Conceptualization, methodology and investigation, S.T. and P.V. with the support of the Research Team of the Observatory for News Innovation in the Information Society (OI2), a collaborative project between Radio Televisión Española (RTVE) and the Autonomous University of Barcelona. All authors have read and agreed to the published version of the manuscript.

Funding: This research was funded by Observatory for News Innovation in the Information Society (OI2), a collaborative project between Radio Televisión Española (RTVE) and the Autonomous University of Barcelona.

Institutional Review Board Statement: Not applicable.

Informed Consent Statement: Not applicable.

Data Availability Statement: Not applicable.

Conflicts of Interest: The author declares no conflict of interest.

\section{References}

Beckett, Charlie. 2019. New Powers, New Responsabilities. A Global Survey of Journalism and Artificial Intelligence. London: London School of Economics.

Berlanga de Jesús, Antonio. 2016. El camino desde la Inteligencia Artificial al Big Data. Revista de Estadística y Sociedad 68: 9-11.

Calvo-Rubio, Luis, and María Ufarte-Ruiz. 2020. Percepción de docentes universitarios, estudiantes, responsables de innovación y periodistas sobre el uso de inteligencia artificial en periodismo. El Profesional de la Información 29: e290109. [CrossRef]

Carlson, Matt. 2015. The Robotic Reporter: Automated journalism and the redefinition of labor, compositional forms, and journalistic authority. Digital Journalism 3: 416-31. [CrossRef]

Caswell, David, and Konstantin Dörr. 2018. Automated journalism 2.0: Event-driven narratives. Journalism Practice 12: 477-96. 
Codina, Lluis. 2017. Revisiones bibliográficas y cómo llevarlas a cabo con garantías: Systematic reviews y Salsa Framework. Lluís Codina, April 20.

Comisión Europea. 2020. Libro Blanco sobre la inteligencia artificial, un enfoque europeo orientado a la excelencia y la confianza. Bruselas: COMISIÓN EUROPEA.

Danzon-Chambaud, Samuel. 2021. A systematic review of automated journalism scholarship: Guidelines and suggestions for future research. Open Research Europe 1: 4. [CrossRef]

Denzin, Norman K., and Yvonna S. Lincoln. 2017. The SAGE Handbook of Qualitative Research. Newcastle: SAGE Publications, ISBN 978 1412974172.

García, Xosé L., and Ángel Vizoso. 2021. Periodismo de alta tecnología: Signo de los tiempos digitales del tercer milenio. El Profesional de la Información 30: 1.

Graefe, Andreas. 2016. Guide to automated journalism. Tow Center for Digital Journalism. Available online: https://www.researchgate. net/publication/289529155_Guide_to_Automated_Journalism (accessed on 30 October 2021).

Manfredi, Sánchez Juan Luis, Ufarte Ruiz, and María José. 2020. Inteligencia artificial y periodismo: Una herramienta contra la desinformación. Revista CIDOB d'Afers Internacionals 124: 49-72. [CrossRef]

Muratova, Nozima, Alton Grizzle, and Dilfuza Mirzakhedova. 2019. Media and Information Literacy in Journalism: A Handbook for Journalists and Journalism Educators. Paris: United Nations Educational, Scientific and Cultural Organization.

Ramírez-Montoya, M., and F. García-Peñalvo. 2018. Co-creation and open innovation: Systematic literature review. [Co-creación e innovación abierta: Revisión sistemática de literatura]. Comunicar 54: 9-18. [CrossRef]

Ramírez-Montoya, María, and Jairo Lugo-Ocando. 2020. Revisión sistemática de métodos mixtos en el marco de la innovación educativa. Comunicar 65: 9-20. [CrossRef]

Rivas-de-Roca, Rubén. 2021. Oportunidades de la robotización en el periodismo local: El caso de 'Mittmedia'. Index.comunicación 11: 165-85. [CrossRef]

Salaverría, Ramón, and Alberto García. 2008. La convergencia tecnológica en los medios de comunicación: Retos para el periodismo. Trípodos 23: 31-47.

Stott, Leda, and Xosé Rami. 2014. Metodología para el desarrollo de estudios de caso. Madrid: UPM.

Tejedor-Calvo, Santiago, Luis M. Romero-Rodríguez, Andrés Moncada-Moncada, and Mariana Alencar-Dornelles. 2020. Journalism that tells the future: Possibilities and journalistic scenarios for augmented reality. Profesional de la Información 29: e290602. [CrossRef]

Túñez, José Miguel, and Santiago Tejedor. 2019. Inteligencia artificial y periodismo [presentación del monográfico]. Doxa Comunicación 29: 163-68. [CrossRef]

Ufarte, María, Luis Mauricio Calvo, and José Francisco Murcia. 2020. Los desafíos éticos del periodismo en la era de la inteligencia artificial. Estudios sobre el Mensaje Periodístico. Madrid: Universidad Complutense de Madrid.

Vaccari, Cristian, and Andrew Chadwick. 2020. Deepfakes and disinformation: Exploring the impact of synthetic political vídeo on deception, uncertainty and trust in news. Social Media and Society 6. [CrossRef]

Vállez, Mari, and Lluís Codina. 2018. Periodismo computacional: Evolución, casos y herramientas. El Profesional de la Información 27: 759-68. [CrossRef]

Villoro, Juan. 2017. Periodismo Robot. En El Periódico. Available online: https://www.elperiodico.com/es/opinion/20150815 / periodismo-robot-4433311 (accessed on 1 November 2021).

Vivar, Flores. 2019. Inteligencia artificial y periodismo: Diluyendo el impacto de la desinformación y las noticias falsas a través de los bots. Doxa Comunicación 29: 197-212.

Whittaker, Jason. 2018. Tech Giants, Artificial Intelligence, and the Future of Journalism. London: Routledge.

Yacuzzi, E. 2005. El estudio de caso como metodología de investigación: Teoría, mecanismos causales, validación. Serie Documentos de Trabajo 296: 1-38. 